\title{
区分モード合成法による振動音響連成系の固有值解析*
}

\author{
古 屋 耕 平*1, 吉 村 卓 也*2
}

\section{Component Mode Synthesis (CMS) for Vibro-Acoustic System}

\author{
Kohei FURUYA*3 and Takuya YOSHIMURA \\ ${ }^{* 3}$ Graduate School of Engineering, Tokyo Metropolitan University, \\ 1-1 Minamiosawa, Hachioji-shi, Tokyo, 192-0397 Japan
}

\begin{abstract}
In Vibro-Acoustic System, [I] complex eigenvalue analysis and [II] CMS (unconstrained mode, without residual) are widely used for eigenvalue analysis. The method [I] needs huge computer resources, but it can obtain the exact eigen value and vector. In the opposite, the method [II] needs fewer resources, but accuracy of eigen-vector is not acceptable in some cases. To improve the accuracy, [III] CMS (unconstrained mode, with residual) can be used. But the method [III] deteriorates the advantage of the method [II], because physical degrees need to be remained in the equation of motion. In this paper, [IV] novel CMS method, based on unconstrained mode and residual mode, is proposed. The required computer resource is less than the methods [III], because the equation of motion is described on the modal coordinates. And the accuracy is better than the method [II]. In this paper, applying the methods [I][II] and the proposed method [IV] to finite element models, it is shown that the proposed method is one of the effective methods for the eigenvalue analysis of Vibro-Acoustic System.
\end{abstract}

Key Words: Component Mode Synthesis, Sound and Acoustic, Coupled Vibration, Eigenvalue Analysis, Modal Anaysis, Finite Element Method

\section{1. 緒言}

自動車室内の騒音は，自動車を評価する一つの基準 として使用者に認識されるようになり, 厳しい設計目 標が設定されている。.さらに開発期間の短縮，開発コ ス卜低減などの要求から CAE(Computer Aided Engineering)，特に低周波騒音を対象とした場合，有 限要素法(FEM)による振動騒音特性の予測が重要な役 割を果たしている.

FEM による車室内(閉空間)の振動騒音特性の予測 では，一般に振動音響連成解析が行われる。 そして萩 原(1)らが示した振動音響連成系(以下，連成系)の固有べ クトルの直交性に基づいたモード解析が，現象理解の ための有効なツールとして利用されている.

連成系の特性方程式は非対称行列で構成されている が, 計算過程を簡単にするために特性方程式を対称化 し固有值解析を行うことが多い. その一つの方法とし て複素固有值解析 ${ }^{(2)}$ (以下, 方法[I])が知られている. 方法[门により連成系の厳密な固有値, 固有べクトルを 計算可能であるが計算負荷は大きい. 文献(2)には同自 由度の対称行列の固有値問題と比較して 2 倍から 5 倍 の計算負荷になることが記述されている.

* 原稿受付 2007 年 2 月 5 日.

*1 正員, 東京都立大学大学院工学研究科(画192-0397 八王子 市南大沢 1-1).

*2 正員, 首都大学東京都市教養学部(画 192-0397 八王子市南 大沢 1-1).

E-mail : furuya-kouhei@c.metro-u.ac.jp
一方で計算負荷を低減させるために，連成系固有べ クトルの構造系成分(变位)と音響系成分(音圧)を，構造 系，音響系単体(非連成系)の固有べクトルの重ね合わ せで表し，自由度を低減する不拘束モード合成法(以下， 方法[II])が提案されている( ${ }^{(3)}$. 方法[II]により計算負荷 は大幅に低減されるが，精度の良い結果を得るために 多くの固有べクトルを採用しなければならない場合が ある.

このような採用固有べクトルの増加を抑えるために 剩余剛性を考慮した拘束モード合成法(4)(5)が提案さ れている。しかし，特性方程式に物理座標の自由度が 残り，方法[I]と比較して計算負荷が大きいことが問題 として残る.

以上の背景を踏まえ，本論文では剩余剛性を考慮し た不拘束モード合成法(以下，方法[III])を検討する. 方法[III]の一般構造物への適用は従来から行われてお $\zeta^{(6)}$, 特性方程式の自由度を採用した固有べクトルの 数まで低減することができる. 方法[III]は物体内での 内力の釣り合いに基礎をおいている．しかし，振動音 響連成系では，変位と音圧という異なる物理量を扱う ため内力の鈎り合い式は成立せず, 従来からの式展開 を適用すると運動方程式に物理座標が残る。よって 本論文では内力を固有ベクトルの重ね合わせで近似 し, 特性方程式をモード座標で表す不拘束モード合 
成法を提案する(以下, 方法[IV]). 方法[IV]で得られ る特性方程式の自由度は方法[II]の2倍程度に抑えられ， 解の精度も改善される。

本論文では方法[I], [II], [III]の特徴について記述し, 提案する方法[IV]を展開する。そそして有限要素モデル へ方法[I]，[II]，[IV]を適用し，提案法が計算精度, 計 算負荷の点で有用であることを示す。

\section{主な記号}
C：連成行列
D：減衰行列
f: カベクトル
$h:$ 採用剩余モード数
$\mathbf{K}$ : 剛性行列
$\ell:$ 採用モード数
M：質量行列
$N$ : 自由度
$\mathbf{R}$ ：剩余モード行列
$\mathbf{T}$ : 座標変換行列

$\mathbf{x}, \mathbf{X}$ : 非連成系固有ベクト, 及び行列

$\mathbf{Z}$ ：剩余コンプライアンス行列

$\alpha$ ：内部自由度 $\beta$ ：境界自由度

$\phi$ : 連成系固有ベクトル $\boldsymbol{\eta}$ : 剩余モ一ド奇与ベクル

$\lambda$ : 固有值 $\Theta$ : 座標変換行列

$v$ : 速度ポテンシャル $\omega_{\mathrm{c}}$ : 剩余計算周波数

$\boldsymbol{\xi}$ : モード寄与ベタル
()$_{\mathrm{A}}$ : 音響系成分
()$_{S}$ : 構造系成分

( ) ${ }^{\mathrm{T}}$ : 転置

()$^{-1}:$ 逆行列

\section{2. 従来法の概要}

$2 \cdot 1$ 複素固有值解析 ${ }^{(2)}$ 特性方程式を対称化し, 固有值解析を行う複素固有值解析について記述する. 振動音響連成系の特性方程式は次式で表される。

$$
\begin{aligned}
{[\mathbf{K}-\lambda \mathbf{M}\}\left\{\left\{\begin{array}{l}
\phi_{\mathrm{S}} \\
\phi_{\mathrm{A}}
\end{array}\right\}\right.} & =\left\{\begin{array}{l}
\mathbf{0} \\
\mathbf{0}
\end{array}\right\} \\
\mathbf{K}=\left[\begin{array}{cc}
\mathbf{K}_{\mathrm{S}}-\mathbf{C} \\
\mathbf{0} & \mathbf{K}_{\mathrm{A}}
\end{array}\right], & \mathbf{M}=\left[\begin{array}{lr}
\mathbf{M}_{\mathrm{S}} & \mathbf{0} \\
\mathbf{C}^{\mathrm{T}} & \mathbf{M}_{\mathrm{A}}
\end{array}\right]
\end{aligned}
$$

ここで速度ポテンシャル $v$ を次式とおく。

$$
\phi_{\mathrm{A}}=\dot{v}=j \sqrt{\lambda} v
$$

式(2)を式(1)へ代入し整理すると, 次式のような対称 行列の特性方程式を得る.

$$
\begin{aligned}
& {[\tilde{\mathbf{K}}+j \sqrt{\lambda} \tilde{\mathbf{D}}-\lambda \tilde{\mathbf{M}}]\{\mathbf{y}\}=\{\mathbf{0}\}} \\
& \tilde{\mathbf{K}} \equiv\left[\begin{array}{cc}
\mathbf{K}_{\mathrm{S}} & \mathbf{0} \\
\mathbf{0} & -\mathbf{K}_{\mathrm{A}}
\end{array}\right], \quad \tilde{\mathbf{D}} \equiv\left[\begin{array}{cc}
\mathbf{0} & -\mathbf{C} \\
-\mathbf{C}^{\mathrm{T}} & \mathbf{0}
\end{array}\right] \\
& \tilde{\mathbf{M}} \equiv\left[\begin{array}{cc}
\mathbf{M}_{\mathrm{S}} & \mathbf{0} \\
\mathbf{0} & -\mathbf{M}_{\mathrm{A}}
\end{array}\right], \quad\{\mathbf{y}\} \equiv\left\{\begin{array}{c}
\phi_{\mathrm{S}} \\
v
\end{array}\right\}
\end{aligned}
$$

式(3)の固有值解析を行うことで式(1)の厳密な固有値 (実数), 固有べクトル(実数)を得ることができるが, 計算負荷は大きい.

\section{$2 \cdot 2$ 剩余剛性を考慮しない不拘束モード合成法 ${ }^{(3)}$}

剩余剛性を考慮しない不拘束モード合成法による自 由度低減の流れと特徴を記述する. 連成系固有べクト ルの構造系成分 $\phi_{S}$ (変位), 音響系成分 $\phi_{\mathrm{A}}($ 音圧)を構造系, 音響系単体(非連成状態)の固有べクトルの重ね合わせ で表現できると仮定する。

$$
\begin{aligned}
\left\{\begin{array}{l}
\phi_{\mathrm{S}} \\
\phi_{\mathrm{A}}
\end{array}\right\} & =\left[\begin{array}{cc}
\mathbf{X}_{\mathrm{S}} & \mathbf{0} \\
\mathbf{0} & \mathbf{X}_{\mathrm{A}}
\end{array}\right]\left\{\begin{array}{l}
\xi_{\mathrm{S}} \\
\xi_{\mathrm{A}}
\end{array}\right\}=[\mathbf{T}]\{\xi\} \\
\mathbf{X}_{\mathrm{S}} & =\left[\mathbf{x}_{\mathrm{S}, 1} \cdots \mathbf{x}_{\mathrm{S}, \ell_{\mathrm{S}}}\right], \quad \mathbf{X}_{\mathrm{A}}=\left[\begin{array}{lll}
\mathbf{x}_{\mathrm{A}, 1} & \cdots & \mathbf{x}_{\mathrm{A}, \ell_{\mathrm{A}}}
\end{array}\right]
\end{aligned}
$$

ここで $\mathbf{X}_{S}$ は採用した構造系の1次から $\ell_{S}$ 次までの固 有べクトルの行列， $\mathbf{x}_{\mathrm{A}}$ は採用した音響系の 1 次から $\ell_{\mathrm{A}}$ 次までの固有べクトルの行列を表す. $\mathbf{X}_{\mathrm{S}}, \mathbf{X}_{\mathrm{A}}$ の第 $r$ 列 $\mathbf{x}_{\mathrm{S}, r}, \mathbf{x}_{\mathrm{A}, r}$ は $r$ 次の固有べクトルを表す.

$$
\begin{aligned}
& {\left[\mathbf{K}_{\mathrm{S}}-\lambda_{\mathrm{S}, r} \mathbf{M}_{\mathrm{S}}\right]\left\{\mathbf{x}_{\mathrm{S}, r}\right\}=\{\mathbf{0}\}} \\
& {\left[\mathbf{K}_{\mathrm{A}}-\lambda_{\mathrm{A}, r} \mathbf{M}_{\mathrm{A}}\right]\left\{\mathbf{x}_{\mathrm{A}, r}\right\}=\{\mathbf{0}\}}
\end{aligned}
$$

式(4)を式(1)へ代入し, 左から $[\mathbf{T}]^{\mathrm{T}}$ を乗じると次式の モード座標上の特性方程式が得られる.

$$
\begin{aligned}
& \quad\left(\left[\begin{array}{cc}
\mathbf{k}_{\mathrm{S}} & -\mathbf{c} \\
\mathbf{0} & \mathbf{k}_{\mathrm{A}}
\end{array}\right]-\lambda\left[\begin{array}{cc}
\mathbf{m}_{\mathrm{S}} & \mathbf{0} \\
\mathbf{c}^{\mathrm{T}} & \mathbf{m}_{\mathrm{A}}
\end{array}\right]\right)\left\{\begin{array}{l}
\xi_{\mathrm{S}} \\
\xi_{\mathrm{A}}
\end{array}\right\}=\left\{\begin{array}{l}
\mathbf{0} \\
\mathbf{0}
\end{array}\right\} \quad(6) \\
& \mathbf{k}_{\mathrm{S}}=\mathbf{X}_{\mathrm{S}}^{\mathrm{T}} \mathbf{K}_{\mathrm{S}} \mathbf{X}_{\mathrm{S}}, \quad \mathbf{m}_{\mathrm{S}}=\mathbf{X}_{\mathrm{S}}^{\mathrm{T}} \mathbf{M}_{\mathrm{S}} \mathbf{X}_{\mathrm{S}}, \quad \mathbf{c}=\mathbf{X}_{\mathrm{S}}^{\mathrm{T}} \mathbf{C} \mathbf{X}_{\mathrm{A}} \\
& \mathbf{k}_{\mathrm{A}}=\mathbf{X}_{\mathrm{A}}^{\mathrm{T}} \mathbf{K}_{\mathrm{A}} \mathbf{X}_{\mathrm{A}}, \quad \mathbf{m}_{\mathrm{A}}=\mathbf{X}_{\mathrm{A}}^{\mathrm{T}} \mathbf{M}_{\mathrm{A}} \mathbf{X}_{\mathrm{A}}
\end{aligned}
$$

式(6)は依然として非対称であるが，自由度は採用する 非連成系の固有ベクトルの数 $\ell_{\mathrm{S}}+\ell_{\mathrm{A}}$ まで低減され, 固 有值解析が容易に実行できる. 式(6)で得られた固有值 は連成系固有值の近似を表し, $\xi_{S}, \xi_{\mathrm{A}}$ を式(4)へ代入 することで連成系固有べクトルの近似が得られる.

本手法の注意点は式(4)の仮定によって生じる計算誤 差である.ここで式(1)を各行で展開し整理すると

$$
\begin{aligned}
& {\left[\mathbf{K}_{\mathrm{S}}-\lambda \mathbf{M}_{\mathrm{S}}\right]\left\{\phi_{\mathrm{S}}\right\}=\left\{\mathbf{f}_{\mathrm{S}}\right\}} \\
& {\left[\mathbf{K}_{\mathrm{A}}-\lambda \mathbf{M}_{\mathrm{A}}\right]\left\{\phi_{\mathrm{A}}\right\}=\left\{\mathbf{f}_{\mathrm{A}}\right\}} \\
& \mathbf{f}_{\mathrm{S}}=[\mathbf{C}\}\left\{\phi_{\mathrm{A}}\right\} \\
& \mathbf{f}_{\mathrm{A}}=\lambda[\mathbf{C}]^{\mathrm{T}}\left\{\phi_{\mathrm{S}}\right\}
\end{aligned}
$$

$\mathbf{f}_{\mathrm{S}}$ は振動音響連成の際に構造系が音響系から受ける力, $\mathbf{f}_{\mathrm{A}}$ は音響系が構造系から受ける力(体積加速度)を表す。 式(5)および式(7)からわかるように，不拘束モード 合成法では $\phi_{S}$ を音響系からの力 $\mathbf{f}_{\mathrm{S}}$ を受けない状態の固 有べクトル $\mathbf{X}_{\mathrm{S}}$ の重ね合わせで表現している. 同様に $\phi_{\mathrm{A}}$ を構造系からの体積加速度 $\mathbf{f}_{\mathrm{A}}$ を受けない状態, すなわ ち剛壁に囲まれた状態の固有べクトル $\mathbf{X}_{\mathrm{A}}$ (以下, 定在 波モード)の重ね合わせで表現している．よって $\phi_{\mathrm{S}}, \phi_{\mathrm{A}}$ が $\mathbf{X}_{\mathrm{S}}, \mathbf{X}_{\mathrm{A}}$ で表現できないような変形を生じている場 合に計算䛊差が大きくなる。 
特に $\phi_{\mathrm{A}}$ の成分のうち構造系と接している音響系節点 や，その周辺に位置する音響系節点で計算誤差が顕著 にあらわれる。これは構造系の振動によって発生する 局所的な音圧分布(例えば，放射状の音圧分布)が，少 数の定在波モードの重ね合わせでは表現できないため である。このため精度の良い結果を得るためには一般 に多くの固有べクトルを採用しなければならない.

\section{$2 \cdot 3$ 剩余剛性を考慮した不拘束モード合成法}

採用固有べクトルの増加を抑えるために，従来から の剩余剛性を考慮した不拘束モード合成法 ${ }^{(6)}$ を適用し た際の式展開を記述する，次式のように連成系固有べ クトルの構造系成分 $\phi_{\mathrm{S}} を, 1$ 次から施次までの非連成 系固有べクトルの行列 $\mathbf{x}_{\mathrm{s}}$ と, $\ell_{\mathrm{S}}+1$ 次以上の固有べク トルの影響を表す剩余コンプライアンス行列 $\mathbf{Z}_{\mathrm{S}}$ (付録 参照)の和で表す。

$$
\left\{\begin{array}{c}
\phi_{\mathrm{S}, \alpha} \\
\phi_{\mathrm{S}, \beta}
\end{array}\right\}=\left[\begin{array}{c}
\mathbf{X}_{\mathrm{S}, \alpha} \\
\mathbf{X}_{\mathrm{S}, \beta}
\end{array}\right]\left\{\xi_{\mathrm{s}}\right\}+\left[\begin{array}{ll}
\mathbf{Z}_{\mathrm{S}, \alpha \alpha} & \mathbf{Z}_{\mathrm{S}, \alpha \beta} \\
\mathbf{Z}_{\mathrm{s}, \beta \alpha} & \mathbf{Z}_{\mathrm{s}, \beta \beta}
\end{array}\right]\left\{\begin{array}{c}
\mathbf{0} \\
\mathbf{f}_{\mathrm{s}, \beta}
\end{array}\right\}
$$

ßは構造系と音響系が接している境界自由度成分を表 し， $\alpha$ は内部自由度成分を表す． $\mathbf{f}_{\mathrm{S}, \beta}$ は式(8)で示され た $\mathbf{f}_{\mathrm{S}}$ の成分を表し， $\alpha$ 成分は零である. 音響系も同 様に考え，連成系の特性方程式の縮約を行うと結果と して次式の特性方程式を得る。

$$
\begin{aligned}
& \left(\left[\begin{array}{cc}
\mathbf{k}_{\mathrm{S}}^{\prime} & -\mathbf{c}^{\prime} \\
\mathbf{0} & \mathbf{k}_{\mathrm{A}}^{\prime}
\end{array}\right]-\lambda\left[\begin{array}{cc}
\mathbf{m}_{\mathrm{S}}^{\prime} & \mathbf{0} \\
\mathbf{c}^{\prime \mathrm{T}} & \mathbf{m}_{\mathrm{A}}^{\prime}
\end{array}\right]\right)\left[\begin{array}{c}
\xi_{\mathrm{S}} \\
\phi_{\mathrm{S}, \beta} \\
\xi_{\mathrm{A}} \\
\phi_{\mathrm{A}, \beta}
\end{array}\right\}=\left\{\begin{array}{l}
\mathbf{0} \\
\mathbf{0} \\
\mathbf{0} \\
\mathbf{0}
\end{array}\right\} \\
& \mathbf{k}_{\mathrm{S}}^{\prime}=\left[\begin{array}{cc}
\mathbf{k}_{\mathrm{S}}+\mathbf{X}_{\mathrm{S}, \beta}^{\mathrm{T}} \mathbf{Z}_{\mathrm{S}, \beta \beta}^{-1} \mathbf{X}_{\mathrm{S}, \beta}-\mathbf{X}_{\mathrm{S}, \beta}^{\mathrm{T}} \mathbf{Z}_{\mathrm{S}, \beta \beta}^{-1} \\
-\mathbf{Z}_{\mathrm{S}, \beta \beta}^{-1} \mathbf{X}_{\mathrm{S}, \beta} & \mathbf{Z}_{\mathrm{S}, \beta \beta}^{-1}
\end{array}\right], \\
& \mathbf{m}_{\mathrm{S}}^{\prime}=\left[\begin{array}{cc}
\mathbf{m}_{\mathrm{S}} & \mathbf{0} \\
\mathbf{0} & \mathbf{0}
\end{array}\right], \quad \mathbf{c}^{\prime}=\left[\begin{array}{ll}
\mathbf{0} & \mathbf{0} \\
\mathbf{0} & \mathbf{C}_{\beta \beta}
\end{array}\right]
\end{aligned}
$$

$\mathbf{k}_{\mathrm{A}}^{\prime}, \mathbf{m}_{\mathrm{A}}{ }_{\mathrm{A}}$ も同様の形式で表される. $\mathbf{C}_{\beta}$ は連成行列 $\mathbf{C}$ の成分に対応した成分である. 式(10)の $\phi_{S, \beta}, \phi_{A, \beta}$ に 対応した行を展開すると次式を得る。

$$
\left[\begin{array}{cc}
\mathbf{Z}_{\mathrm{S}, \beta \beta}^{-1} & -\mathbf{C}_{\beta \beta} \\
-\lambda \mathbf{C}_{\beta \beta}^{\mathrm{T}} & \mathbf{Z}_{\mathrm{A}, \beta \beta}^{-1}
\end{array}\right]\left\{\begin{array}{l}
\phi_{\mathrm{S}, \beta} \\
\phi_{\mathrm{A}, \beta}
\end{array}\right\}=\left\{\begin{array}{l}
{\left[\mathbf{Z}_{\mathrm{S}, \beta \beta}^{-1} \mathbf{X}_{\mathrm{S}, \beta}\right]\left\{\xi_{\mathrm{S}}\right\}} \\
{\left[\mathbf{Z}_{\mathrm{A}, \beta \beta}^{-1} \mathbf{X}_{\mathrm{A}, \beta}\right]\left\{\xi_{\mathrm{A}}\right\}}
\end{array}\right\}
$$

式(11)の左辺第二行に未知数入が含まれているため, 式 (11)を颃,,$\phi_{\mathrm{A}, \beta}$ について解くことができず, 特性方程 式に物理座標か残ってしまう。そのため剩余剛性を考 慮することで計算精度は改善されるが, 計算負荷は剩 余剛性を考慮しない場合と比較して大きくなる.

\section{3. 提案する不拘束モード合成法}

3 ・1 展 開 内力を固有べクトルの重ね合わせで 近似し，特性方程式をモード座標で表す方法を提案す る。連成系固有べクトル ル $\mathbf{X}$ と剩余コンプライアンス行列 $\mathbf{Z} て ゙$ 次式のように表 す.

$$
\begin{aligned}
& \left.\left\{\phi_{S}\right\}=\left[\mathbf{X}_{\mathrm{S}}\right]\left\{\xi_{\mathrm{S}}\right\}+\left[\mathbf{z}_{\mathrm{S}}\right] \mathbf{f}_{\mathrm{S}}\right\} \\
& \left\{\phi_{\mathrm{A}}\right\}=\left[\mathbf{X}_{\mathrm{A}}\right]\left\{\xi_{\mathrm{A}}\right\}+\left[\mathbf{z}_{\mathrm{A}}\right]\left\{\mathbf{f}_{\mathrm{A}}\right\}
\end{aligned}
$$

さらに各系へ作用する力 $\mathbf{f} を \mathbf{X}_{\mathrm{S}} ， \mathbf{X}_{\mathrm{A}}$ の重ね合わせで 表現できると仮定すると，式(8)より

$$
\begin{aligned}
& \mathbf{f}_{\mathrm{S}} \cong[\mathbf{C}]\left[\mathbf{x}_{\mathrm{A}}^{\prime}\right]\left\{\boldsymbol{\eta}_{\mathrm{S}}\right\} \\
& \mathbf{f}_{\mathrm{A}} \cong[\mathbf{C}]^{\mathrm{T}}\left[\mathbf{x}_{\mathrm{S}}^{\prime}\right]\left\{\boldsymbol{\eta}_{\mathrm{A}}\right\}
\end{aligned}
$$

$\mathbf{X}_{\mathrm{S}}^{\prime}$ は採用次数を 1 次から $h_{\mathrm{A}}$ 次とした構造系単体の固 有べクトルを表す(添え字は以降の展開のために A とす る)。同様に $\mathbf{X}_{\mathrm{A}}^{\prime}$ は 1 次から $h_{\mathrm{S}}$ 次までの音響系単体の 固有べクトルである。またりは対するモード奇与べ クトルを表す. 式(13)を式(12)へ代入すると

$$
\begin{gathered}
\left\{\phi_{\mathrm{S}}\right\}=\left[\mathbf{X}_{\mathrm{S}}\right]\left\{\xi_{\mathrm{S}}\right\}+\left[\mathbf{R}_{\mathrm{S}}\right]\left\{\boldsymbol{\eta}_{\mathrm{S}}\right\} \\
\left\{\phi_{\mathrm{A}}\right\}=\left[\mathbf{x}_{\mathrm{A}}\right]\left\{\xi_{\mathrm{A}}\right\}+\left[\mathbf{R}_{\mathrm{A}}\right]\left\{\boldsymbol{\eta}_{\mathrm{A}}\right\} \\
\left.\mathbf{R}_{\mathrm{S}}=\left[\mathbf{z}_{\mathrm{S}}\right] \mathbf{C}\right]\left[\mathbf{X}_{\mathrm{A}}^{\prime}\right], \quad \mathbf{R}_{\mathrm{A}}=\left[\mathbf{z}_{\mathrm{A}}\right][\mathbf{C}]^{\mathrm{T}}\left[\mathbf{X}_{\mathrm{S}}^{\prime}\right]
\end{gathered}
$$

$\mathbf{R}_{\mathrm{S}}$ は構造系へ $[\mathbf{C}]\left[\mathbf{X}_{\mathrm{A}}^{\prime}\right]$ の力が作用したときの剩余剛性 の変形形状を表す。本論文では $\mathbf{R}$ を剩余モード行列， $\mathbf{R}$ の各列を剩余モードと呼ぶ. $h_{\mathrm{S}}$ は剩余モードの採用 数を表し， $\eta_{S}$ は剩余モードの $\phi_{S}$ への寄与を表している. $\mathbf{R}_{\mathrm{A}}, h_{\mathrm{A}}, \eta_{\mathrm{A}}$ も同様の意味を持つ.

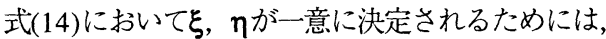
$\mathbf{X}_{\mathrm{S}}$ と $\mathbf{R}_{\mathrm{S}}$ の各列， $\mathbf{X}_{\mathrm{A}}$ と $\mathbf{R}_{\mathrm{A}}$ の各列が線形独立でなけれ ばならない.よって自由度の観点から $\ell_{\mathrm{S}}+h_{\mathrm{S}} \leqq N_{\mathrm{S}}$ (構造 系自由度)， $\ell_{\mathrm{A}}+h_{\mathrm{A}} \leqq N_{\mathrm{A}}$ (音響系自由度)を满足する必要 がある。またそれらの条件を満たした場合であっても， $\mathbf{R}$ の各列が線形従属になる場合があり，独立な成分を 取り出さなければならない。この方法については次節 以降で論じる. 以下では $\mathbf{x}_{\mathrm{S}}$ と $\mathbf{R}_{\mathrm{S}}$ の各列， $\mathbf{x}_{\mathrm{A}}$ と $\mathbf{R}_{\mathrm{A}}$ の 各列が線形独立であると仮定し議論する．式(14)を整 理すると

$$
\left.\left\{\begin{array}{c}
\phi_{S} \\
\phi_{\mathrm{A}}
\end{array}\right\}=\left[\begin{array}{cccc}
\mathbf{X}_{\mathrm{S}} & \mathbf{0} & \mathbf{R}_{\mathrm{S}} & \mathbf{0} \\
\mathbf{0} & \mathbf{X}_{\mathrm{A}} & \mathbf{0} & \mathbf{R}_{\mathrm{A}}
\end{array}\right]\left\{\begin{array}{c}
\xi_{\mathrm{S}} \\
\xi_{\mathrm{A}} \\
\boldsymbol{\eta}_{\mathrm{S}} \\
\boldsymbol{\eta}_{\mathrm{A}}
\end{array}\right\}=[\boldsymbol{\Theta}]\right\}\left\{\begin{array}{l}
\xi \\
\boldsymbol{\eta}
\end{array}\right\}
$$


式(15)を式(1)へ代入し, 左から $[\Theta]^{\mathrm{T}}$ を乗じると自由度 $\ell_{\mathrm{S}}+\ell_{\mathrm{A}}+h_{\mathrm{S}}+h_{\mathrm{A}}$ の特性方程式が得られる.

$$
[\tilde{\mathbf{k}}-\lambda \tilde{\mathbf{m}}]\}\left\{\begin{array}{l}
\xi \\
\boldsymbol{\eta}
\end{array}\right\}=\left\{\begin{array}{l}
\mathbf{0} \\
\mathbf{0}
\end{array}\right\}
$$

$$
\tilde{\mathbf{k}}=[\boldsymbol{\Theta}]^{\mathrm{T}}\left[\mathbf{K}[\boldsymbol{\Theta}], \quad \tilde{\mathbf{m}}=[\boldsymbol{\Theta}]^{\mathrm{T}}[\mathbf{M}][\boldsymbol{\Theta}]\right.
$$

式(16)の特性行列は密行列に近くなるが, 自由度が小 さいため容易に解くことができる.

$3 \cdot 2$ 剩余モードの採用数に対する制約 剩余 モードの採用数 $h$ の制約について考える. 連成行列 $\mathbf{C}$ は $\mathrm{C}_{\beta \beta}$ 以外の成分が零の行列であるから，各系へ作用 する力 $\mathbf{f}$ は，構造系と音響系が接した境界自由度成分 $\beta$ のみ非零となる。

$$
\begin{gathered}
\left\{\begin{array}{c}
\left\{\mathbf{f}_{\mathrm{S}, \alpha}\right. \\
\mathbf{f}_{\mathrm{S}, \beta}
\end{array}\right\}=[\mathbf{C}]\left\{\phi_{\mathrm{A}}\right\}=\left[\begin{array}{ll}
\mathbf{0} & \mathbf{0} \\
\mathbf{0} & \mathbf{C}_{\beta \beta}
\end{array}\right]\left\{\begin{array}{l}
\phi_{\mathrm{A}, \alpha} \\
\phi_{\mathrm{A}, \beta}
\end{array}\right\}=\left\{\begin{array}{c}
\mathbf{0} \\
\mathbf{C}_{\beta \beta} \phi_{\mathrm{A}, \beta}
\end{array}\right\} \\
\left\{\begin{array}{l}
\mathbf{f}_{\mathrm{A}, \alpha} \\
\mathbf{f}_{\mathrm{A}, \beta}
\end{array}\right\}=\lambda[\mathbf{C}]^{\mathrm{T}}\left\{\phi_{\mathrm{S}}\right\}=\left\{\begin{array}{c}
\mathbf{0} \\
\lambda \mathbf{C}_{\beta \beta}^{\mathrm{T}} \phi_{\mathrm{S}, \beta}
\end{array}\right\}
\end{gathered}
$$

よって $\mathbf{f}_{\mathrm{S}}$ の自由度は構造系の境界自由度 $N_{\mathrm{S}, \beta}$ で表され る. $\mathbf{f}_{\mathrm{S}}$ の近似式(13)の自由度は $h_{\mathrm{S}}$ であるから， $h_{\mathrm{S}} \leqq$ $N_{\mathrm{S}, \beta}$ を満足しなければならない. 音響系も同様に, $h_{\mathrm{A}}$ $\leqq N_{\mathrm{A}, \beta}$ (音響系境界自由度)を満足しなければならない，

$3 \cdot 3$ モード寄与,$\eta \eta$ 差異提案法では境界 面に作用する力 $\mathbf{f}$ を非連成状態の固有べクトルの重ね 合わせで表現し，その寄与を新たな未知変数りとおい た. 式(8)の定義から考えると物理的には次式の従属関 係が成立する。

$$
\xi_{\mathrm{A}}=\eta_{\mathrm{S}}, \quad \lambda \xi_{\mathrm{S}}=\boldsymbol{\eta}_{\mathrm{A}}
$$

しかし，近似という観点ではこれらを独立に扱うこと で精度が向上する。これはそが全系の $\phi$ を近似するのに 対して，クは境界面における力 $\mathbf{f}$ のを近似するため, fの精度か改善され，結果として $\phi$ の精度も改善される からである。

$3 \cdot 4$ 剩余モードの線形独立成分採用した非 連成系の固有べクトル $\mathbf{X}_{\mathrm{S}}$ と線形独立な剩余モードの 列を $\mathbf{R}_{\mathrm{S}}$ から取り出す方法について考える. 剩余コン プライアンス行列 $\mathbf{Z}_{\mathrm{S}}$ は, 式(A.3)で定義され, $r=1, \ldots, \ell_{\mathrm{S}}$ 次までの固有べクトル成分を含まない.よ って $\mathbf{R}_{\mathrm{S}}$ の列の中で線形独立な列は， $\mathbf{X}_{\mathrm{S}}$ の各列と線形 独立となる。

線形独立な $\mathbf{R}_{\mathrm{S}}$ の列を取り出す簡易的な方法は, 次 式のように $\mathbf{R}_{\mathrm{S}}{ }^{\mathrm{T}}$ と $\mathbf{R}_{\mathrm{S}}$ の積を $\mathrm{LU}$ 分解して得られる行 列Uの非零対角成分を調べることである.

$$
[\mathbf{L}] \mathbf{U}]=\left[\mathbf{R}_{\mathrm{S}}\right]^{\mathrm{T}}\left[\mathbf{R}_{\mathrm{S}}\right]
$$

$\left[\mathbf{R}_{\mathrm{S}}\right]^{\mathrm{T}}\left[\mathbf{R}_{\mathrm{S}}\right]$ は $h_{\mathrm{S}} \times h_{\mathrm{S}}$ の行列であるから LU 分解が容易に 実行できる．以上の議論は音響系成分についても同様 に成立する。

3 -5 提案法のまとめ提案する不拘束モード合 成法の特徴を以下にまとめる.

(1). 構造系, 音響系へ作用する力を, 構造系, 音響系 単体の固有べクトルで近似する.

(2). (1)の結果から連成系固有ベクトルを構造系, 音響系の固有ベクトルと㮃余モードで近似する.

(3). 縮約された特性方程式の自由度は採用した固有べ クトルと剩余モードの数 $\left(\ell_{\mathrm{S}}+\ell_{\mathrm{A}}+h_{\mathrm{S}}+h_{\mathrm{A}}\right)$ となる.

提案法を適用するための制約は以下である.

(4). $\ell_{\mathrm{S}}+h_{\mathrm{S}} \leqq N_{\mathrm{S}}$ (構造系自由度), $\ell_{\mathrm{A}}+h_{\mathrm{A}} \leqq N_{\mathrm{A}}$ (音響系自由度)

(5). $h_{\mathrm{S}} \leqq N_{\mathrm{S}, \beta}$ (構造系境界自由度)， $h_{\mathrm{A}} \leqq N_{\mathrm{A}, \beta}$ (音響系境 界自由度)

(6). $\mathbf{X}_{\mathrm{S}}$ と $\mathbf{R}_{\mathrm{S}}$ の各列, $\mathbf{X}_{\mathrm{A}}$ と $\mathbf{R}_{\mathrm{A}}$ の各列は線形独立.

(7). 剩余コンプライアンス行列 $\mathbf{Z}$ の精度を保障するた め, 求める連成系固有値 $\lambda$ は $\lambda \leqq \lambda_{\mathrm{S}, \mathrm{SS}}, \lambda_{\mathrm{A}, \ell \mathrm{A}}$ であるこ と(付録参照) . $\lambda_{\mathrm{S}, \mathrm{t}}, \lambda_{\mathrm{A}, \ell \mathrm{A}}$ は $\ell_{\mathrm{S}}$ 次, $\ell_{\mathrm{A}}$ 次の構造系, 音 響系単体の固有値を表す。

\section{4. 提案法の検証 1}

4・1 対象有限要素モデル [I]複素固有值解析, [II] 剩余無し不拘束モード合成法, [IV]提案する不拘束 モード合成法を有限要素モデルへ適用し，精度と計算 負荷について検証を行う。

図 1 に対象とする有限要素モデルを示す. 対象モデ ルは板が音響空間の底面と連成しており，板の四辺は 完全拘束されている. また板と接していない音響空間 の面は剛壁と接している. 本章では従来法との比較検 証を容易にするため，構造系の剩余剛性が無視できる よう板厚を $20 \mathrm{~mm}$ とした. $20 \mathrm{~mm}$ の板の場合, 連成系 固有ベクトルの構造系成分 $\phi_{S}$ は少数の構造系単体の固 有ベクトル $\mathrm{X}_{\mathrm{S}}$ で十分に表現できる.よって[II][IV]の 方法において構造系採用固有ベクトル数を $\ell_{\mathrm{S}}=10$ とし た.また対象モデルの材料定数，自由度を表 1 にまと め.

以下では, MSC/Nastran を利用し方法[I]の解析を 行う．その際に特性行列 $\mathbf{M}, \mathbf{K}$ を出力させ，その行列 を数值計算ソフトウェア MATLAB で作成した方法 [II][IV]で解析する。計算機は CPU Pentium $43.2 \mathrm{GHz}$, Memory 2.0GB, Windows PCを利用した。 
Table 1 Properties of FE model

\begin{tabular}{|c|c|}
\hline Total DOF $N=N_{\mathrm{S}}+N_{\mathrm{A}}$ & 9295 \\
\hline \multicolumn{2}{|c|}{ Properties of Structure } \\
\hline Young's modulus & $207[\mathrm{GPa}]$ \\
\hline Density & $7.90 \times 10^{3}\left[\mathrm{~kg} / \mathrm{m}^{3}\right]$ \\
\hline Poisson's ratio & 0.30 \\
\hline Thickness of shell & $0.020[\mathrm{~m}]$ \\
\hline DOF $N_{\mathrm{S}}$ & 2070 \\
\hline Properties of Acoustics \\
\hline Sound velocity & $343.0[\mathrm{~m} / \mathrm{s}]$ \\
\hline Density of air & $1.21\left[\mathrm{~kg} / \mathrm{m}^{3}\right]$ \\
\hline DOF $N_{\mathrm{A}}$ & 7225 \\
\hline
\end{tabular}

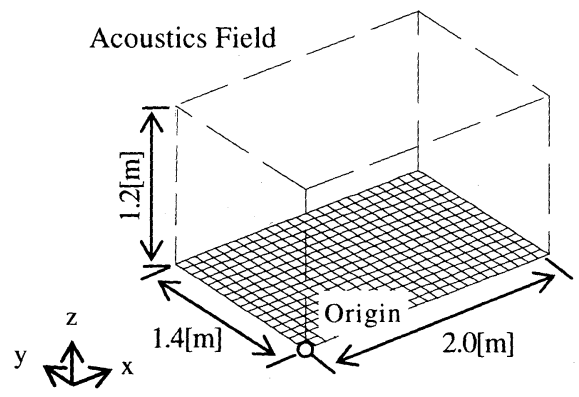

Fig. 1 Objective FE model

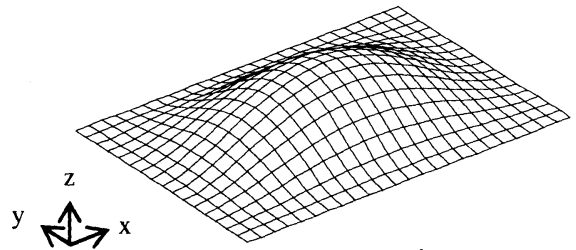

Fig. 2 Structural Deformation of $2^{\text {nd }}$ Coupled Mode, by [I]Complex Eigenvalue Analysis
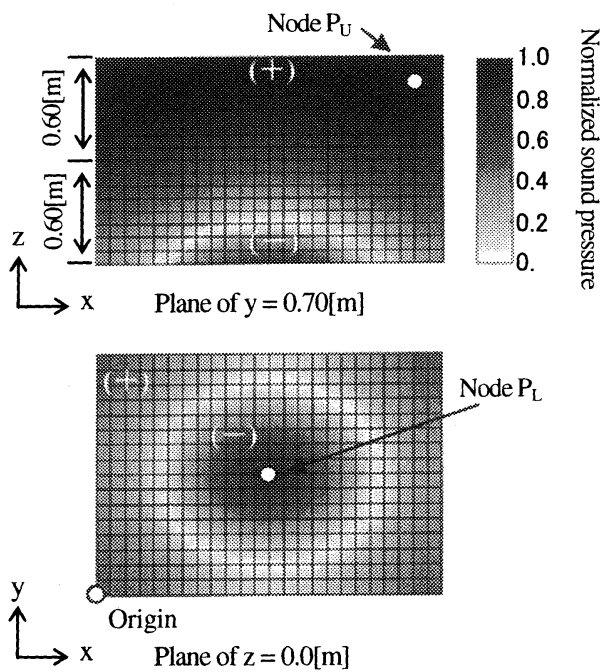

Fig. 3 Sound Pressure Distribution of $2^{\text {nd }}$ Coupled Mode, by [I]Complex Eigenvalue Analysis
Nastran と MATLAB を併用した理由は，計算負荷が 大きいため物理座標での複素固有值解析が MATLAB 上で行えなかったためである.

\section{4・2［1]複素固有值解析の結果 複素固有値} 解析で得られた連成 2 次 (連成 1 次は $\mathrm{OHz}$ の音響系定在 波が主体のモード), 固有振動数 $f=69.37[\mathrm{~Hz}]$ の固有べ クトルの構造系成分を図 2，音響系成分を図 3 に示す。 図 2 から構造系か膜振動している様子がわかる. 図 3 は最大值で正規化された音圧分布を示しており，図中 の“十”,“一”は，その周辺の音圧の符号を表す。図 3 上は $\mathrm{y}=0.7[\mathrm{~m}]$ の $\mathrm{xz}$ 面音圧分布, 図 3 下は構造系と接 している $\mathrm{z}=0.0[\mathrm{~m}]$ の $\mathrm{xy}$ 面音圧分布を示している. 図 3 が示すように構造系に近い下部節点 $(\mathrm{z}<0.6[\mathrm{~m}])$ で放射 状の音圧分布がみられ，また上部節点 $(\mathrm{z}>0.6[\mathrm{~m}])$ では， 音圧が一様に高いレベルで分布している様子がわかる.

\section{4・3［II]剩余無し不拘束モード合成法の結果}

剩余剛性を考慮しない不拘束モード合成法で得られ た結果を示す。図 4 は音響系の採用固有べクトルを $\ell_{\mathrm{A}}=10$ から 400 まで変化させ得られた連成 2次の固有 ベクトルと，方法[I]で得られた固有べクトル間の相関 を示している．添え字は対象とした成分を表す．例と して音響采の境界自由度 $\beta$ の相関 $r_{\mathrm{A}, \beta}$ は次式で表される。

$$
r_{\mathrm{A}, \beta}=\frac{\left|\left\{\phi_{\mathrm{A}, \beta}^{[\mathrm{I}]}\right\}\left\{\phi_{\mathrm{A}, \beta}^{[\mathrm{II}]}\right\}\right|}{\left\|\phi_{\mathrm{A}, \beta}^{[\mathrm{I}]}\right\| \cdot\left\|\phi_{\mathrm{A}, \beta}^{[\mathrm{II}]}\right\|}
$$

添之字[I][I] は計算方法, |・は絶対値, ॥・川はべク トルノルムを表す．構造系, 音響系の相関 $r_{\mathrm{S}}, r_{\mathrm{A}}$ は $\ell_{\mathrm{A}}=10$ であっても良い值を示している. 一方で $r_{\mathrm{A}, \beta}$ の 值は低く, 構造系と接している音響系成分で精度が悪 いことが分かる.

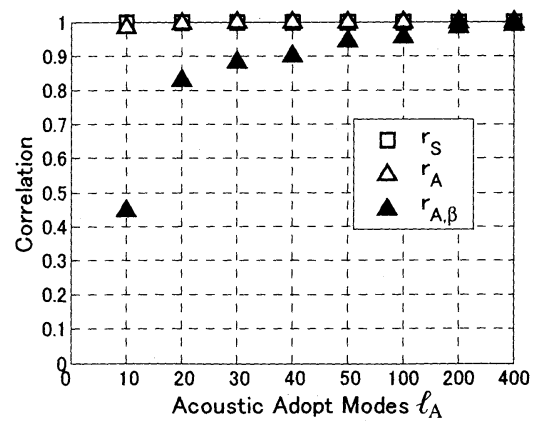

Fig.4 Correlation of method [I] and method [II] 
図 5 は，方法[I][I]で得られた連成 2次の固有べクト ルをそれぞれ川 $\phi_{\mathrm{S}} \|=1$ になるように正規化したときの， 音響系節点 $\mathrm{P}_{\mathrm{U}}, \mathrm{P}_{\mathrm{L}}$ (図 3)の值の比を表している. 節点 $\mathrm{P}_{\mathrm{U}}$ の比は $\ell_{\mathrm{A}}=20$ で方法 $[1]$ で得られた值とほぼ等しくな つている. 一方, 節点 $\mathrm{P}_{\mathrm{L}}$ の比は $\ell_{\mathrm{A}}=400$ の場合であっ ても 0.8 程度であり，2.2節で述べたように，構造系と 接している音響系節点では精度が著しく低下すること が分かる。

図 6 に $\ell_{\mathrm{A}}=10$ の場合の音圧分布を示寸. $\ell_{\mathrm{A}}=10$ の場合, 大まかな音圧分布は正しく表現されているが，下部節 点の放射状の音圧分布は正しく表現されていない.

図 7 に方法[I][I]で得られた連成 2 次の固有振動数の 相対誤差と $\ell_{\mathrm{A}}$ の関係を示す. 連成 2 次の固有振動数は 構造系が主体であるため, $\ell_{\mathrm{A}}=10$ であっても方法[I]と の誤差が+0.07\%という良い近似を与えている。また $\ell_{\mathrm{A}}$ が増加すると共に固有振動数が+方向から方法[I]で 得られた值へ収束している様子がわかる.

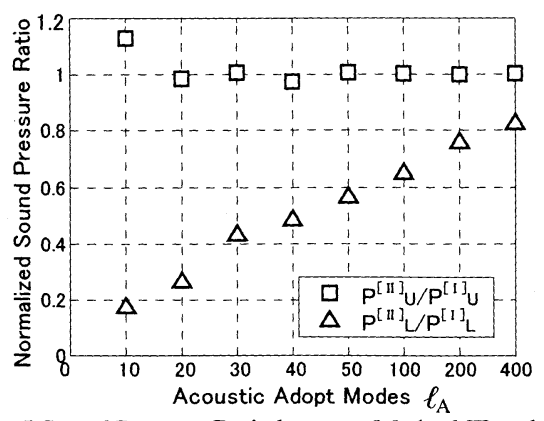

Fig.5 Sound Pressure Ratio between Method [I] and [II]
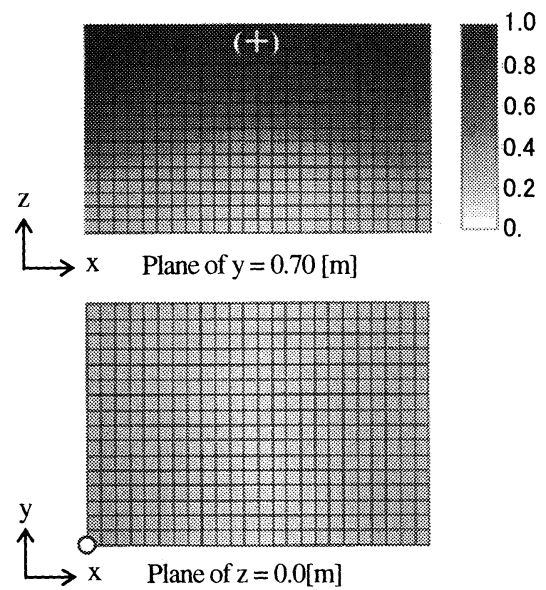

Fig. 6 [II] CMS without Residual $\ell_{\mathrm{A}}=10$. SP Distribution

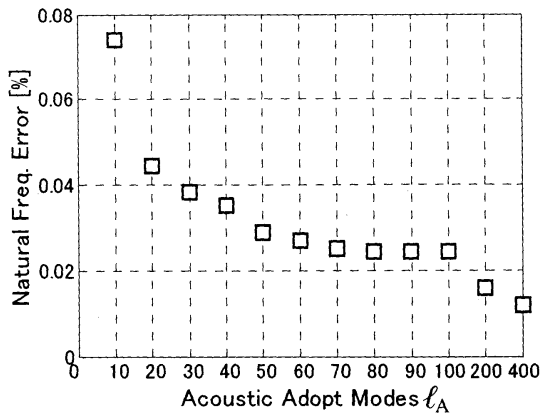

Fig. 7 Natural Freq. Error of Method [II]

Table 2 Correlation and Normalized Ratio of Method [II] [IV]

\begin{tabular}{|c|c|c|c|c|c|}
\hline & $r_{\mathrm{S}}$ & $r_{\mathrm{A}}$ & $r_{\mathrm{A} \beta}$ & $\mathrm{P}_{\mathrm{U}} / \mathrm{P}^{\left[{ }_{\mathrm{U}}\right.}$ & $\mathrm{P}_{\mathrm{L}} / \mathrm{P}^{\left[{ }^{[]}\right.} \mathrm{L}$ \\
\hline [II] $\ell_{\mathrm{A}}=10$ & 1.00 & 0.985 & 0.446 & 1.123 & 0.169 \\
\hline [II] $\ell_{\mathrm{A}}=50$ & 1.00 & 0.999 & 0.943 & 1.007 & 0.564 \\
\hline $\begin{array}{c}\text { [IV] } \\
\ell_{\mathrm{A}}=h_{\mathrm{S}}=h_{\mathrm{A}}=10\end{array}$ & 1.00 & 1.00 & 0.999 & 0.966 & 0.955 \\
\hline \multicolumn{5}{|c|}{$\ell_{\mathrm{S}}=10$ in Methods [II] [IV] } \\
\hline
\end{tabular}

Table 3 Natural Frequency of $2^{\text {nd }}$ Coupled Mode.

\begin{tabular}{|l|c|}
\hline \multicolumn{1}{|c|}{ Method } & Natural Freq. [Hz] \\
\hline [ I ] Complex Eigenvalue Analysis & 69.37 \\
\hline [II] CMS without Residual $\ell_{\mathrm{A}}=10$ & 69.42 \\
\hline [II] CMS without Residual $\ell_{\mathrm{A}}=50$ & 69.39 \\
\hline [IV] Proposed CMS $\ell_{\mathrm{A}}=h_{\mathrm{S}}=h_{\mathrm{A}}=10$ & 69.37 \\
\hline \multicolumn{2}{|c|}{$\ell_{\mathrm{S}}=10$ in Methods [II] [IV]]. } \\
\hline
\end{tabular}

4・4 [IV]提案法の結果［IV]提案する剩余剛性を 考慮した不拘束モード合成法を適用する. 固有べクト ルの採用数を $\ell_{\mathrm{S}}=\ell_{\mathrm{A}}=10$, 同様に剩余モードの採用数を $h_{\mathrm{S}}=h_{\mathrm{A}}=10$ とした，方法[I]で得られた固有べクトルと の相関， $\mathrm{P}_{\mathrm{U}}, \mathrm{P}_{\mathrm{L}}$ の值の比を表 2 に示す．提案法では相 関 $r$ はほほ $1.0, \mathrm{P}_{\mathrm{U}} ， \mathrm{P}_{\mathrm{L}}$ の值も $5 \%$ 程度の誤差であり良 好な結果であった．表 3 に得られた連成 2 次の固有振 動数をまとめる. 提案法では固有振動数の值は方法[1] で得られた值と小数点以下 2 桁まで一致した.

この結果から剩余モードを導入することで，固有值 解析の精度を改善できることか確認できた。

$4 \cdot 5$ 計算時間の比較 本節では各方法の計算時 間の比較を行う. 方法[II]の採用固有ベクトル数を $\ell_{\mathrm{S}}=10, \ell_{\mathrm{A}}=50$, 方法[IV]では $\ell_{\mathrm{S}}=\ell_{\mathrm{A}}=10, h_{\mathrm{S}}=h_{\mathrm{A}}=10$ と した. また参考として方法[III]の従来からの利余剛性 を考慮した不拘束モード合成法を $\ell_{\mathrm{S}}=\ell_{\mathrm{A}}=10$ の条件で 適用した。

特性方程式の自由度(DOF) と計算時間の関係を調べ るため, 有限要素モデルの $\mathrm{x}$ 軸方向の要素分割を変え， 
初期状態(DOF=9295)の 2,3,4 倍の自由度で計算を行 った，本論文では Nastran と MATLAB を併用してい るため方法[I]と他の方法の計算時間を直接比較できな い. そのため Nastran で行った方法[I][II]の固有值解 析に要した時間を図 8 に, MATLAB で行った方法[I] [III], [IV]の固有値解析に要した時間を図 9 に示す。こ こで固有值解析に要した時間とは行列 M,K の縮約過 程の計算時間を含んだものである.

図 8 に示すように自由度が小さい場合，方法[I][II] は同程度の計算時間であるが，自由度に対する計算時 間の傾きが異なっている。このことから大自由度の問 題では方法[1]の適用が困難となることが予想される.

図 9 に示すように方法[W]の計算負荷は大きく， 自由度を 4 倍にした計算では解析が実行できなか った。

一方，提案する方法[IV]では少数の非連成系固有べ クトルを求めるだけで良く, 特性方程式の自由度も小 さいため計算時間は短く, $\ell_{\mathrm{A}}=50$ とした方法[II]の半分 程度であった。この結果から提案する方法[IV]の計算 負荷に対する有効性が確認できる。

\section{5. 提案法の検証 2}

本章では図 10 に示す有限要素モデルを利用し，提 案法の精度検証を行う. 対象有限要素モデルは，直方 体の音響系が厚さ $5 \mathrm{~mm}$ の板で囲まれたものである. 板厚以外の材料定数は表 1 の值を利用した。構造系は 底面 $(\mathrm{z}=0.0[\mathrm{~m}])$ の四隅を完全拘束されている. 図 10 の モデルは板厚がモデルの寸法に対して薄く，音響系の 六面が構造系と接しているため, 構造系が受ける音響 系からの圧力, 音響系が受ける構造系からの体積加速 度が大きい，そのため構造系，音響系，双方の剩余剛 性の影響が大きく，前章で対象としたものより一般的 なモデルとなっている.

以下では[I]複素固有值解析で得られた $200 \mathrm{~Hz}$ まで の 134 個の固有べクトルと, [IV]提案法により得られ た 134 個の固有べクトルを比較する。提案法では $250 \mathrm{~Hz}$ までの構造系単体の固有べクトル $\left(\ell_{S}=150\right)$ と, 音響系単体の固有べクトル $\left(\ell_{\mathrm{A}}=15\right)$ を採用した。 また剰 余モードは $h_{\mathrm{S}}=15, h_{\mathrm{S}}=150$ とした.

方法[I][IV]で得られた固有べクトル間の相関 $r_{\mathrm{S}}, r_{\mathrm{A}}$, $r_{\mathrm{A}, \beta}$ は 0.999 以上の良好な值を示した。 また方法[ []

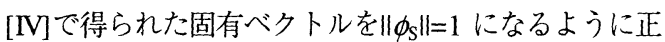
規化したときの，音響系の境界自由度成分 $\phi_{\mathrm{A}, \beta}$ のノル 厶比を図 11 に示す。境界自由度の誤差は土1\%程度で 良好な結果であった．また固有振動数の相対誤差を図
12 に示す. 固有振動数の誤差は最大で $8 \times 10^{-3}[\%]$ と, 非常に小さい值であった．またその誤差はすべて正で あった．以上の結果から，一般的な問題に対しても提 案法により精度の良い固有值解析が行えることを確認 した.

[ [I]Complex Eigenvalue Analysis $\triangle[I I] C M S$ without Residual $\ell_{\mathrm{S}}=10, \ell_{\mathrm{A}}=50$

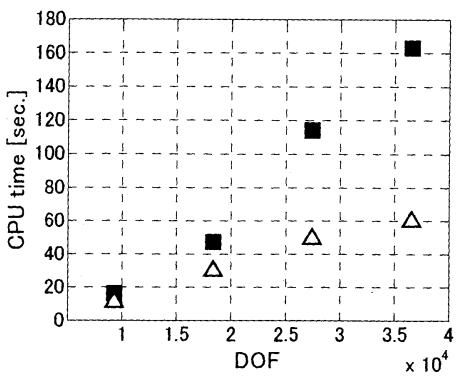

Fig. 8 CPU time of Methods [I] [II] on Nastran

$\triangle$ [II CMS without Residual $\ell_{\mathrm{S}}=10, \ell_{\mathrm{A}}=50$

- [III] CMS with Residual $\ell_{\mathrm{S}}=\ell_{\mathrm{A}}=10$

O [IV] Proposed CMS $\ell_{\mathrm{S}}=\ell_{\mathrm{A}}=h_{\mathrm{S}}=h_{\mathrm{A}}=10$

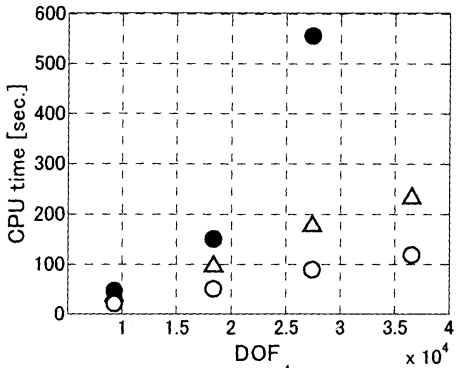

* Method [III] is failed at $3.7 \times 10^{4} \mathrm{DOF}$ (shortage of memory) Fig. 9 CPU time of Methods [II] [III] [IV] on MATLAB

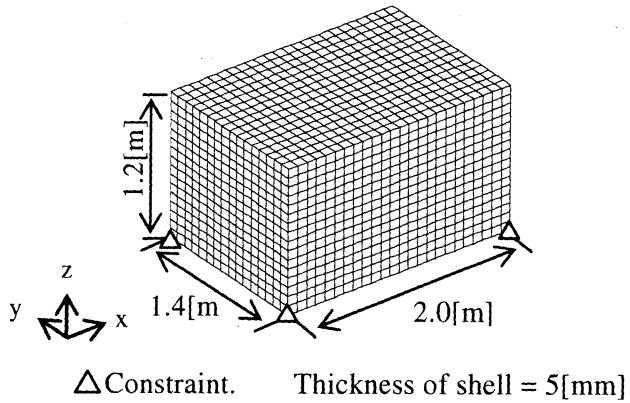

Fig. 10 Objective FE model 


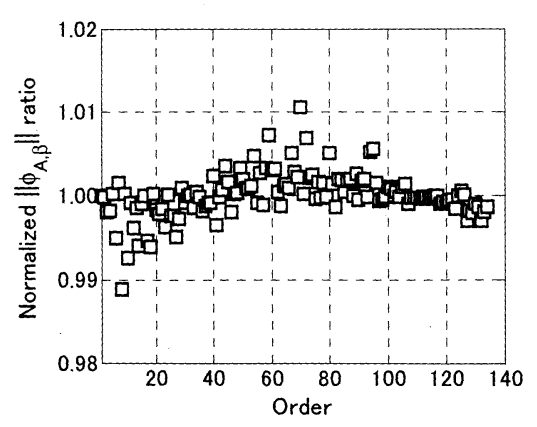

Fig. 11 Normalized $\left\|\phi_{A, \beta}\right\|$ Ratio between Method [I] and [IV]

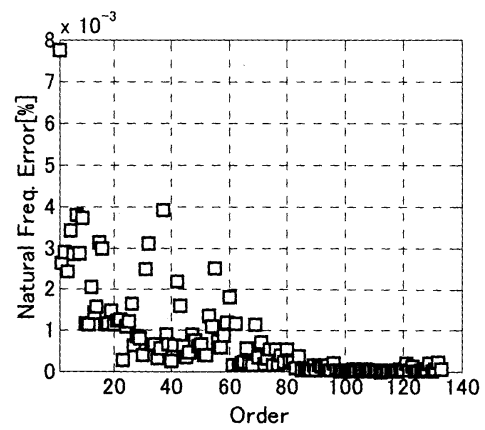

Fig. 12 Natural Freq. Error of Method [IV]

\section{6. 結}

\section{論}

本論文の内容を以下にまとめる.

（1）振動音響連成系の固有值解析における計算負荷低 減を目的とした新しい不拘束モ一ド合成法を提案 した.

（2）提案法と従来法を, 構造系剰余剛性の影響が無視 できる有限要素モデル(図 1) 適用した：そして提 案法が従来法と比較して, 計算精度, 計算負荷の 点で有効であることを示した。

（3）構造系, 音響系, 双方の剩余剛性の影響が大きい 有限要素モデル(図 10) へ提案法を適用し，良好な 結果を得た。この結果から提案法により一般の問 題に対しても精度の良い結果が得られることを確 認した.

提案法は若干の数値解析上の技術を必要とするが, そ の精度と計算負荷の利点により, その欠点は補われる ものと考えている.

\section{付 録}

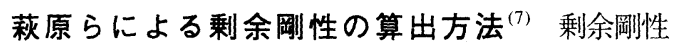
を考慮しない不拘束モ一ド合成法において，連成系固 有ベクトルの構造系成分 $\phi_{\mathrm{S}}$ を非連成系固有ベクトル $\mathbf{x}_{\mathrm{S}, r}\left(r=1, \ldots, \ell_{\mathrm{S}}\right)$ の重ね合わせで表したことの数学的な 意味は，逆行列を次式で近似したことである.

$$
\left[\mathbf{K}_{\mathrm{S}}-\lambda \mathbf{M}_{\mathrm{s}}\right]^{-1} \cong \sum_{r=1}^{\rho_{\mathrm{S}}} \frac{\left\{\mathbf{x}_{\mathrm{S}, r}\right\}\left\{\mathbf{x}_{\mathrm{S}, r}\right\}^{\mathrm{T}}}{\lambda_{\mathrm{s}, r}-\lambda}
$$

このとき採用しなかった 影響は唾余剛性と呼ばれ次式で表される.

$$
\mathbf{Z}_{\mathrm{S} \lambda}(\lambda)=\left[\mathbf{K}_{\mathrm{s}}-\lambda \mathbf{M}_{\mathrm{S}}\right]^{-1}-\sum_{r=1}^{f_{\mathrm{s}}} \frac{\left.\left\{\mathbf{x}_{\mathrm{s}, r}\right\} \mathbf{X}_{\mathrm{s}, r}\right\}^{\mathrm{T}}}{\lambda_{\mathrm{s}, r}-\lambda}
$$

上式の剰余剛性はコンプライアンスの次元を持つので 剩余コンプライアンス行列と呼ばれる． $\mathbf{Z}_{\mathrm{S} \lambda}$ は入が未知 であるため厳密な值を求めることができない. しかし， その精度の良い近似が次式の定数行列 $\mathbf{Z}_{\mathrm{S}}$ で与えられ ることが導かれている。

$$
\mathbf{z}_{\mathrm{s}}=\left[\mathbf{K}_{\mathrm{s}}-\omega_{\mathrm{c}}^{2} \mathbf{M}_{\mathrm{s}}\right]^{-1}-\sum_{r=1}^{\ell_{\mathrm{s}}} \frac{\left\{\mathbf{x}_{\mathrm{S}, r}\right\}\left\{\mathbf{x}_{\mathrm{s}, r}\right\}^{\mathrm{T}}}{\lambda_{\mathrm{S}, r}-\omega_{\mathrm{c}}^{2}}
$$

ここで $\omega_{\mathrm{c}}$ は定数で， $\omega_{\mathrm{c}}$ の值によって近似精度が変化 する. $\omega_{\mathrm{c}}$ が求めようとするれに近くなるほど近似精度 は良くなる. 本論文では採用した最高次 $\left(\ell_{\mathrm{S}}\right.$ 次 $)$ の固有 振動数以下で近似精度が保たれるように次式の值を利 用する。

$$
\omega_{\mathrm{c}}=\sqrt{\frac{1}{2}\left(\lambda_{\mathrm{s}, 1}+\lambda_{\mathrm{s}, \ell_{\mathrm{s}}}\right)}
$$

以上の議論は音響系においても同様に成立する。

\section{文献}

(1) Hagiwara, I., et al., Technical Development of Eigenmode Sensitivity Analysis for Coupled AcousticStructural Systems, Transactions of the Japan Society of Mechanical Engineers, Series C, Vol. 56, No. 527(1990), pp. 1704-1711.

(2) MSC software, MSC.Nastran Reference Manual 2001, p580.

(3) R.Freymann, Dynamic Response of Coupled Structural-Acoustic Systems, Journal of Low Frequency Noise and Vibration, Vol.14, No.1, 1995.

(4) Matthias Maess, et al., Component Mode Synthesis for Efficient Structure-Acoustic Simulation of Piping system, International Modal Analysis Conference XXIV, 2006.

(5) Ichikawa, T., et al., Component Mode Synthesis for Large-Scale Coupled Structure-Acoustic Fluid Interaction Problem, Transactions of the Japan Society of Mechanicál Engineers, Series C, Vol. 61, No. 587, pp. 2718-2724, 1995.

(6) Nagamatsu, A., et al., Building Block Approach (1991), pp.126-130, BAIFUKAN CO., LTD.

(7) Nagamatsu, A., et al., Modal Analysis and Control of Sound and Vibration (1996), pp.139148, CORONA PUBLISHING. 